\title{
Droceedings of פocietieg.
}

\section{NEW YORK PSYCHIATRICAL SOCIETY.}

Stated Meeting, November 6, 1907.

Dr. Adolf Meyer, President, in the chair.

Preliminary Report on the Significance of the Ocular Signs and Symptoms of Dementia Precox as ObServed in a Series of i 5 Consecutive Cases.

By DR. H. H. TYSON AND DR. L. PIERCE CLARK.

The cases were from private practice, clinics, and the metropolitan asylums. Definite changes were invariably found. The fundus changes, as seen clinically, are divided into three stages, in the order of their occurrence. First stage, congestion of the discs, hyperæmia and œdema, dilated veins, contracted arteries, and blurring of the edges of the discs, of varying degrees, constituting a low grade perineuritis of the optic nerve. Second stage, congestion of the nasal side with temporal pallor of discs, dilated veins and contracted arteries. Third stage, pallor of discs, dilated veins, and contracted arteries, constituting partial or complete atrophy of the optic nerve.

All forms of dementia præcox were under study. The more rapidly deteriorating forms show the most marked changes. The cases embraced both users of alcohol and tobacco, and abstainers. Theoretically, the changes are probably due to a vascular toxin from liver or intestinal auto-infective origin. A vascular alteration with odema takes place, resulting in disturbances of nutrition and slow degeneration of the nerve fibers. Cases in the first stage have shown fundus improvement under the usual treatment for intestinal auto-infective toxæmias.

Other eye symptoms found uniformly were: Enlarged pupils, negative sensory reflex, negative psychic reflex, negative Piltz

38 
reflex, diminished corneal sensibility, and concentrically contracted visual fields. No other psychosis presents similar conditions. The findings should be found useful in differential diagnosis, to a certain extent in prognosis, and possibly in the study of the pathogenesis and pathology of dementia præcox. Cases illustrative of the three stages were demonstrated to those members who used the ophthalmoscope.

\section{Discussion.}

Dr. C. E. Atwood, of New York City, had followed the investigations of Dr. Clark and Dr. Tyson, having seen nearly all the cases examined by them, and now looks for the changes in the optic disc and the other eye symptoms in every case of dementia præcox which comes under his observation. In no case so far had he found the symptom-complex wanting. Recently, at the suggestion of Dr. Clark, he had been studying cases of infection, e. g., lead poisoning, quinine poisoning, and cases of typhoid fever and pneumonia, etc., in the hope of finding some similar changes in these conditions which might be of similar origin. Dr. Atwood read the findings in a number of cases examined. In five men with typhoid infection, averaging about 26 days' duration, four of whom smoked and drank, all showed haziness of the disc with some blurring of the edges and fullness of the veins. In one (the non-drinker and non-smoker) there was limitation of the fields to about 30 degrees. In one only (of six weeks' duration) there was an appearance of central fullness (œdema?), the cup not showing. In four women with typhoid, averaging 26 days' duration, the discs in two cases were normal and in the other two, anæmic, the vessels being less full and the surface pale. In three men with pneumonia, all of whom smoked and drank moderately, the fundus in one was normal, and in the other two there was haziness of the edges of the disc with fullness of the veins, but no œdema. In twe post-operative septic cases, one a gangrenous appendicitis, the other an intestinal perforation, both exhibited haziness and venous enlargement, but no œdema. Both of these cases used alcohol and tobacco. A man with partial amblyopia from quinine poisoning (case of Dr. Tyson's) who neither drank nor smoked, showed haziness, congestion and œdema of the nasal 
side, with fullness of the xeins and pallor on the temporal side. Central scotoma was also present. The vision was $2 / 200$ right, $20 / 100$ left. The last case reported was one of infection from lead. A man, aged 44, born in Germany, drank beer, had slight arterio-sclerosis, and had the occupation of making white lead in a factory. For seven months he had had double wrist-drop, and been under treatment in a neighboring town for this and lead colic, etc. Both discs exhibited central œdema, pallor, and enlarged veins. The fields were contracted to 15 degrees for red, Io degrees for green. There was central scotoma principally for red. $\mathrm{V} .=20 / 30$. The examination of seriously ill patients, e. g., with typhoid, etc., at Roosevelt Hospital, was facilitated through the kindness of Professor James, and made possible by the use of the electric ophthalmoscope.

Dr. William Mabon, of New York City, read the report of the findings in examinations of the fundi of 25 patients with dementia præcox and 25 with manic-depressive insanity at the Manhattan State Hospital. These examinations had been made by Dr. -Holden, whose report was as follows: "Blin has reported in a series of observations of dementia præcox patients, a persistent congestion of the optic disc in to per cent, a persistent anæmia in 8 per cent, and an alternating congestion and anæmia in 6 per cent, with intermittent congestion or anæmia in 45 per cent more. However, I wish to say that the color of the optic disc varies within wide physiological limits and many of us do not like to speak of congestion or anæmia of the disc unless the condition is pronounced and palpably abnormal. In none of these 100 eyes examined did I find a congestion or an anæmia that seemed to me significantly abnormal. The color of the disc may be said to depend largely upon the personal equation of the examiner. In the 25 patients with dementia præcox, the outlines of the discs were blurred more than in the average normal eye in 11 patients. In 6 of these II the large veins of the disc and retina were appreciably dilated. In the 25 patients with manic-depressive insanity, on the contrary, there was a blurred outline of the discs in but four patients, and in but two of these were the large veins appreciably dilated. This blurring of the outline of the discs is in many cases of dementia præcox too pronounced to be considered physio- 
logical and must be regarded as pathological. It is due to cloudiness of the nerve-fiber layer of the retina and optic nerve, which in some cases seems to be caused by a cloudy swelling of the nerve fibers which can be individually made out, and in other cases perhaps to an œdema of this layer without swelling of the fibers, or in other cases perhaps to both of these causes combined. In half of the cases in which the outline of the discs was blurred the veins of the retina were, as compared with the arteries, abnormally dilated. The condition may be analogous to the circulatory changes and œdema found in other parts of the body in dementia præcox. In some cases it is so pronounced as to give rise to a characteristic picture, and from the examination of these $25 \mathrm{pa}-$ tients and of about an equal number previously examined, of which complete statistics were not kept, I should judge that the condition was to be found in about half the cases of dementia præcox and rather exceptionally, and in a less pronounced degree, in manic-depressive insanity." In view of Dr. Holden's statement that the condition was to be found in about half of the cases of dementia præcox and exceptionally in manic-depressive insanity, it would seem advisable to make further investigations before reaching the conclusion that these conditions are of diagnostic significance.

Dr. P. C. Knapp, of Boston, called attention to the importance in these cases of refraction errors. In a considerable number of cases of brain disease, especially in cases of headache, he had found such a congestion of the optic disc as had been described, with blurring of its outline so great as to suggest beginning neuritis, but due, as further investigation showed, to a considerable degree of hypermetropia. It would be well to eliminate the possibility of refraction error before assuming changes in the optic disc. Dementia præcox was not the only mental disease, as suggested by Dr. Tyson, in which these changes are noted. They occur in general paralysis in a number of cases, although they are less frequently seen than conditions of optic atrophy. He had seen a number of cases where there was congestion of the disc and haziness of outline in which the changes were indubitably those of low-grade neuritis.

Dr. Adolf Meyer, of New York City, remarked that in order to 
prove that we are dealing with an inflammation and subsequent atrophy of the optic nerve, it would be very desirable to have sufficiently strong evidence of functional disorders of vision. In the absence of visual defect in cases of remission, etc., it remains to be shown that the appearance of the disc is not merely an incidental phenomenon of a general vasomotor difficulty.

Dr. Clark, in closing the discussion, said that in a number of cases at the Vanderbilt Clinic followed independently by $\mathrm{Dr}$. Holden and by Dr. Tyson and himself, the results tallied exactly so far as the disc changes were concerned. In the report just presented Dr. Holden seemed to take it for granted that the only changes were congestion and haziness, whereas these formed only a part of a series of changes. These changes would not be noted unless the entire series were followed. Careful analyses in other types of mental disease had failed to reveal changes which could be confounded with those described. The different phases of the changes described, ranging from the congestive stage to the terminal one of general diffused atrophy of perineuritis, should be borne in mind, otherwise it is impossible to arrive at statistics. Of course there were optic changes in paresis, but this was not often to be differentiated from dementia præcox. He had made it a point to look for the physiological cupping of the disc, and if this could not be noted to look for other features that go with dementia præcox. One hundred and fifteen cases, the number studied, would not establish any of these changes for diagnostic purposes. The work, as stated, was but a preliminary communication and must be verified by more exhaustive studies by many different observers before this eye syndrome could be finally considered as definitely established. The significance of these clinical features was tentative, and might undergo modification, but after two and a half years of investigation he was convinced that there is a characteristic toxic change going on in dementia præcox which must be recognized as a feature of the disease, possibly rendering it a somatic disorder with a mental accompaniment.

Dr. Tyson, in closing the discussion, said, with reference to errors of refraction, that it was only in high degrees that congestion of the disc was found, and that high hypermetropia was found in only one per cent. In atrophy it was only by contraction of the 
field and diminution of visual acuity, with cupping and pallor of the discs and contracted arteries, that the diagnosis was made; and finally that in using the ocular signs and symptoms to aid in making a diagnosis, the entire eye symptom-complex should be used and not only the appearance of the fundus oculi.

\section{The Anxiety Psychoses.}

Dr. George H. Kirby, of New York City, read this paper. The affect of anxiety is of wide occurrence and appears in a variety of psychoses, yet our clinical experience teaches that there is a group of cases in which the anxiety appears to stand out more or less as a fundamental symptom and not in association with additional features that would stamp the disorder as belonging with any other well recognized symptom-complex. These anxious depressions occur mainly in the climacteric period or later in life, yet similar symptom pictures occasionally develop in earlier years. Kraepelin's recent proposal to merge the anxious depressions into the manic-depressive group as "mixed forms" was argued against by the author, who showed that Kraepelin was led to this change of position chiefly because he found that nearly all of the surviving cases of involution depression had terminated in recovery even after a prolonged course. This generalization exemplifies to what an extreme degree the Kraepelinian statistical method may be pushed. The author's material afforded many reasons for keeping the anxious depressions apart from the manic-depressive psychoses-they appear to arise out of a different etiology, show important symptomatological differences, run a different course from the manic-depressive cases and are especially dangerous to the life of the patient. Various factors were mentioned which seem to prepare the ground for the origin of the anxious affect, e. g., intoxications, organic insufficiency, advanced age, etc., and attention was drawn particularly to the great frequency with which the anxious mood arises out of prolonged worries and chronic emotional strains of various kinds. Cases were reported to demonstrate the importance of these psychogenetic elements in the development of the psychoses with anxiety. The cases studied fall into several groups each of which seems to have some prognostic significance. (I) Cases showing a simple form of anxiety 
or general uneasiness, apprehensive anticipations with or without ideas of sin. (2) A severer form showing anxiety, with fear, perplexity, and allo-psychic concepts. (3) Cases presenting the sensory-somatic complex, hypochondriacal trends and feelings of unreality. (4) Cases developing with arterio-sclerosis. The anxious depressions here described are not regarded as a special form of disease, but are considered rather as a type of reaction of fairly characteristic form in the evolution of which a number of factors participate; the psychogenetic features appear to be particularly important. There seems to be a difficulty in adjustment to a situation which would naturally put the patient into an anxious frame of mind. In a smaller group of cases the physical causes seem to be most important and arterio-sclerosis is especially apt to be accompanied by an anxious depression.

\section{Discussion.}

Dr. William Mabon, of New York City, was of the opinion that the anxieties should be kept separate from the manic-depressive group.

Dr. August Hoch, of Bloomingdale, said: "Dreyfus tries to show that melancholia is merely a phase of manic-depressive insanity. Kraepelin agrees with him, as he states in the introduction which he wrote to Dreyfus's book. But to do Kraepelin justice, we must remember that he specially mentions the fact of the differences in duration in the two groups of cases. While Dreyfus has made a valuable contribution in having shown that what most of us, with Kraepelin, regarded as permanent mental dilapidation, is in reality a recoverable condition; there is little gained by merely identifying the two groups of cases. There is no doubt as to a certain relationship, but there is also no doubt as to the differences, and we would have to say that these cases of melancholia are manic-depressive depressions under special conditions with special features and with certain peculiarities in course. It seems to me that we may regard the development of the anxiety and the unreality complex in depression, in other words, those features which characterize the involution melancholias, somewhat in the light of complications, very much as we regard complications in other diseases. By this we emphasize on the one hand 
the relationship and on the other hand the differences. I, therefore, quite agree with Dr. Kirby that it is more profitable to keep the two groups separate. I am also very glad that Dr. Kirby emphasizes the psycho-genetic factors in the development of these cases, and I am quite sure that the work of Dr. Meyer and of Dr. Kirby in this direction is of great value, as it calls attention to many facts which are clear enough when one looks for them, but which have often been singularly disregarded."

Dr. A. R. Diefendorf, of Middletown, Conn., was inclined to agree with Dr. Kirby in his contention for the maintenance of the anxiety psychoses. In his own experience the melancholia of involution was not as prevalent as he had formerly believed. There were cases developing in the involutional period which show anxiety, but are also accompanied by considerable psychometer retardation. These cases which tend to recur should not be confounded with the anxiety psychosis, as they rightfully belong to the manic-depressive group. He had failed to note psychogenetic factors in the origin of his cases as being particularly prominent. In view of the fact that there is often a long prodromal period during which the patient is introspective, symptoms of the disease may be mistaken for psychogenic factors, that is, the patient fails to exhibit anxiety over troubles that have long existed in their life, until they show the first signs of the disease. With reference to the group designated by Dr. Kirby as the arterio-sclerotic group, he saw no reason why they should not be considered as cases of arterio-sclerotic insanity.

Dr. Charles L. Dana, of New York City, said that in private practice one sees many of the anxiety psychoses, though not of so severe a type as those described by Dr. Kirby. It undoubtedly made a clean-cut clinical picture, and to recognize it as a distinct form of melancholia was helpful in the prognosis and in the treatment. At the same time, the more he saw of melancholia the more it seemed to him that the "anxiety complex" occurs not only in the involutional period, but in early life. It was his experience that nearly one-half of the cases of involutional melancholia coming on after 50 or 40 give a history of one or two attacks of " neurasthenia" years before, these often being mild psycho-neuroses calling for no special attention from the psychiatrist. With refer- 
ence to the psychogenetic factor, he believed that the patients who develop these involutional psychoses are generally men and women of rather inferior mental caliber or persons who have worked in an environment which was too strenuous for them, and which, consciously or unconsciously, pulls them down. He could not recall any really brilliant mind that has suffered from involutional insanity. The women belonged to the type of women who have been worriers all their lives, who have had "precisions" and constant anxiety over details, and who were not fitted to carry on easily the work they are appointed to do. Melancholia in all its phases was the same thing, but occurring in different individuals it produced the differences noted. The same definite lesion occurring in one individual would produce melancholia with anxiety, in another retardation and apathy, and in still another, in addition to anxiety there may be self-accusation, or hypochondria. The differences in the clinical picture were due to the original differences in the make-up of the individual. He would represent melancholia by the term $\mathrm{X}$ which meant a definite unknown lesion of the psychical apparatus, some break in association-paths, perhaps, the special characters, of self-reproach, depression, anxiety, retardation, would depend on the physique and character of the individual patient.

Dr. Adolf Meyer, of New York City, pointed out how, after all, a new standpoint, such as that of Kraepelin, of dividing all mental diseases into non-dementing and dementing processes is apt to tend to become a sort of all-embracing system with very few subdivisions. The welcome awaking of interest in the outcome of the disease has finally been pushed to the position of a logical decision which naturally must either fit or not fit ; but such division of all mental disorders would ignore many other matters which have long been thought of and cannot be neglected. The fact that the outcome issue had been neglected for such a long time was no reason for making it an all-embracing issue for all decisions. To argue merely about the outcome would again lead to a great deal of guessing, and from a didactic point of view it would be better to fix the attention upon what is seen in the patient at the time of examination. It would be a much better working principle to try to recognize the concrete difficulties under which the patient la- 
[Jan.

bors, to examine the factors which led up to these difficulties, and to estimate the balance of the forces of the individual to meet the situation. This, in practically all cases of manic-depressive insanity, would naturally lead to the recognition of a non-dementing disorder in harmony with Kraepelin's nosology. Dreyfus's claim that the anxiety depressions are mixed conditions of manic-depressive insanity is another overstretching of a fruitful principle. As soon as one constructs mixed conditions of manic-depressive insanity, practically everything, even normal mental activity, can be included in this category. We already hear that hysteria should be included in the depressive psychoses. With regard to the psycho-genetic nature of the process, he was inclined to consider Dr. Dana's remarks very well to the point. Dr. Diefendorf's exception to the issue might hold for some cases, but it was absolutely undeniable that there is a larger percentage of palpable causes for a depression than in the ordinary manic-depressive insanities. Many manic-depressive depressions in the involutional period begin to show anxieties. As soon as manifestations of manic-depressive features were noted one had symptoms which were of prognostic value. But the fact remains that the pure anxiety states for etiological and practical reasons form a group worth differentiation.

Dr. Kirby, in closing the discussion, referred to Dr. Gregory's suggestion that anxiety is largely a general symptom which occurs in a number of psychoses and recalled the fact that he had emphasized this point in his paper. Anxiety is a prominent feature in a variety of disorders, associated, however, with additional symptoms sufficient to mark the psychosis as belonging with some one of the better known types, thus the anxious alcoholic cases mentioned by Dr. Gregory usually presented distinctive features, particularly in their evolution. He would agree with Dr. Diefendorf's suggestion concerning the grouping of the arterio-sclerotic cases, but in many agitated depressions the arterio-sclerotic basis is apt to be under-estimated or even over-looked for a considerable time, perhaps until some definite cerebral attack occurs. When the arterio-sclerotic nature of the disorder is clear, the proper group would be, of course, the organic brain diseases. He could not subscribe to Dr. Dana's conception of melancholia as a general 
disorder or a single disease, no matter whether it belonged to the manic-depressive or involution type of depression. The cases studied show that the two forms of reactions, certainly when they are are pure, are symptomatically and prognostically different and above all they seem to develop on a different foundation. Provision must be made for a small number of cases which seem to show admixtures or appear to be transitional forms. Many cases of manic-depressive insanity show anxiety, but here it is usually found in a fairly characteristic setting. These cases have nearly always a feeling of insufficiency or show clearly some difficulty of thought or constraint in activity which does not appear in the anxiety psychoses described.

\section{NEW ENGLAND SOCIETY OF PSYCHIATRY.}

Dr. Chas. W. Page, presiding.

The regular semi-annual meeting of the society was held with Dr. E. V. Scribner, at the Grafton Colony of the Worcester Insane Asylum, North Grafton, Thursday, September 19, 1907. In the absence of the president, Dr. Philip C. Knapp, the vicepresident, Dr. Charles W. Page, presided. The paper, "The Cytological Study of the Cerebro-spinal Fluid, by Alzheimer's Method, and its Diagnostic Value in Phychiatry," by Drs. Henry A. Cotton and J. B. Ayer, was read by Dr. Cotton. Dr. Ayer arranged the microscopical demonstration. The following is an abstract of the paper:

The method of Alzheimer for treating the cerebro-spinal fluid, published in the Centralblatt für Nervenheilkunde und Psychiatrie, June 15, 1907, forms the basis for this investigation.

In the opinion of the authors, this method is by far the best devised for studying the cells of the cerebro-spinal fluid as an a1d to diagnosis in mental diseases.

Alzheimer makes use of the precipitation of proteid matter in the fluid by alcohol, and combining with this centrifugalization of the mixture. The cells are caught in the coagulum formed, and the coagulum is then treated as tissue, and the usual stains used 